Title: WP Emplacement Control and Communication Equipment Descriptions
DI: BCA000000-01717-5705-00004 Rev 00

Page: 1 of 18

WBS No.: 1.2.4.7

SCP No.: N/A

QA: N/A

TECHNICAL DOCUMENT TITLE

\title{
WP EMPLACEMENT CONTROL AND COMMUNICATION EQUIPMENT DESCRIPTIONS
}

DOCUMENT IDENTIFIER

BCA000000-01717-5705-00004 REV 00

Prepared by: $\frac{\text { Novman }}{\text { Norman T. Raczka }}$

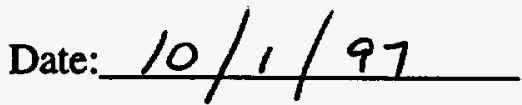

Reviewed by:

Daniel G. McKenzie

Date:

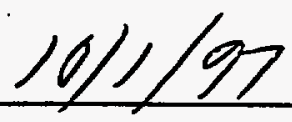

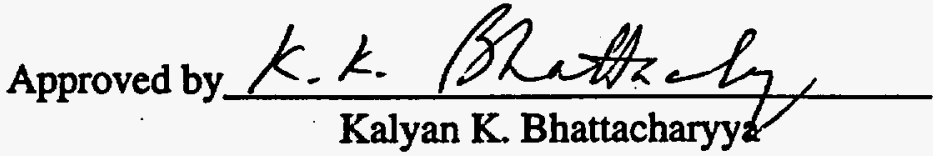

Date: $10 / 2 / 97$ 


\title{
EQUIPMENT DESCRIPTIONS
}

\section{WP EMPLACEMENT CONTROL AND COMMUNICATION EQUIPMENT}

\author{
FY 1997
}

\subsection{OBJECTIVE AND SCOPE}

The objective and scope of this document are to list and briefly describe the major control and communication equipment necessary for waste package emplacement at the proposed nuclear waste repository at Yucca Mountain. Primary performance characteristics and some specialized design features of the required equipment are explained and summarized in the individual subsections of this document. This task was evaluated in accordance with QAP-2-0 and found not to be quality affecting. Therefore, this document was prepared in accordance with NAP-MG-012.

The following control and communication equipment are addressed in this document:

1. Programmable Logic Controllers (PLC's)

2. Leaky Feeder Radio Frequency Communication Equipment

3. Slotted Microwave guide Communication Equipment

4. Vision Systems

5. Radio Control Equipment

6. Enclosure Cooling Systems

\subsection{INPUTS}

The equipment descriptions are based on the design analyses cited below. All design parameters, design assumptions, criteria, codes and standards, and technical references as stated in the analyses are applicable for use in this document. The method used to prepare this document is to summarize the technical features and design parameters of the major equipment discussed in the following analyses.

2.1 Subsurface Waste Package Handling - Remote Control and Data Communication Analysis, DI:BCA000000-01717-0200-00004 Rev 00

2.2 Emplacement System Control and Communication Analysis, DI:BCA000000-01717-0200$00016 \operatorname{Rev} 00$

2.3 Preliminary Analysis of Remote Monitoring \& Robotic Concepts for Performance Confirmation, DI:BCAI00000-01717-0200-00001 Rev 00 
Title: WP Emplacement Control and Communication Equipment Descriptions

Page: 3 of 18

2.4 Overall Development and Emplacement Ventilation Systems, DI:BCA000000-01717-0200$00015 \operatorname{Rev} 00$

\subsection{EQUIPMENT DESCRIPTIONS}

\subsection{PROGRAMMABLE LOGIC CONTROLLERS}

Programmable logic controllers (PLC's) were originally designed to replace relay-based logic systems and solid-state hard-wired logic control panels. Their advantages over these types of systems are that they are easily programmed, highly reliable, flexible, relatively inexpensive, and able to communicate with other plant computers.

A PLC processor examines the status of inputs and controls a process or machine through the generation of control outputs. Combinations of input and output data are referred to as logic. The processor consists of one or more standard or custom microprocessors and other integrated circuits that perform the computing and control functions of the system.

The analyses cited in section 2.0 have discussed installing PLC's on the emplacement gantry and installing PLC networks to control the isolation doors and rail switches. The following sections include preliminary data sheets for this recommended equipment.

\subsubsection{Isolation Door Programmable Logic Controller Processor Data Sheet}
A. Equipment Name:
Isolation Door Programmable Logic Controller
B. Service: Monitor and control the operation of the isolation doors located underground in the repository at the entrance of each emplacement drift.

C. Operating Conditions:

1. Working Location:

2. Elevation:

3. Temperature Range:

4. Humidity:

D. Power Requirements:

1. Input Voltage:

2. Frequency:

3. Wattage:
Below the surface in the main drifts (East, and West) Approximately 1000 to 1200 meters above sea level $10^{\circ} \mathrm{C}$ to $50^{\circ} \mathrm{C}$

TBD
120 Volts AC

$60 \mathrm{~Hz}$

As Required 
E. Equipment Description:

1. Mounting Requirements: Rack mounted

2. Number of Communication Ports:

3 Minimum

3. Communication Protocols Supported:

Ethernet TCP/IP, Data Highway, Remote Input/ Output (I/O) (ports to be user selectable)

4. I/O Card Interface: Yes

5. YO card orientation

6. Maximum length of $\mathrm{VO}$ communication link:

Remote (ie. not in the same rack as the processor)

7. Type of cards supported:

8. Maximum Quantity of Remote I/O Racks:

9. U/O Capacity

10. Memory:

11. Program Scan Time:

12. CMOS-RAM protection:

13. Temperature limits:

14. Humidity:

3,500 meters

Discrete, Analog, Intelligent

15

$2048 \mathrm{I} / \mathrm{O}$ points

48,000 Words

2 milliseconds $/ 1000$ Words

Battery backup

$0^{\circ} \mathrm{C}$ to $60^{\circ} \mathrm{C}$

$5 \%$ to $95 \%$ Relative Humidity (non-condensing)

F. Manufacturers

Possible manufacturers of this equipment include: Allen-Bradley, G.E. Fanuc, Modicon, Reliance Electric, Asea Brown Boveri Inc.

\subsubsection{Rail Switch Programmable Logic Controller (PLC) Processor Data Sheet}
A. Equipment Name:
Rail Switch Programmable Logic Controller (PLC)
B. Service:
Monitor and control the operation of the rail switches located underground in the repository.
C. Operating Conditions:
1. Working Location:
2. Elevation:
3. Temperature Range:
4. Humidity:
Below the surface in the main drifts (North, South, East, and West)
Approximately 1000 to 1200 meters above sea level $10^{\circ} \mathrm{C}$ to $50^{\circ} \mathrm{C}$
TBD 
D. Power Requirements:
1. Input Voltage:
120 Volts AC
2. Frequency:
$60 \mathrm{~Hz}$
3. Wattage:
As Required

E. Equipment Description:

1. Mounting Requirements: Rack mounted

2. Number of Communication Ports:

3 Minimum

3. Communication Protocols Supported:

Ethernet TCP/IP, Data Highway, Remote Input/ Output (VO) (ports to be user selectable)

4. I/O Card Interface: Yes

5. VO card orientation

6. Maximum length of $\mathrm{I} / \mathrm{O}$ communication link:

Remote (ie. not in the same rack as the processor)

3,500 meters

7. Type of cards supported: Discrete, Analog, Intelligent

8. Maximum Quantity of Remote VO Racks:

15

9. I/O Capacity

10. Memory:

2048 I/O points

48,000 Words

11. Program Scan Time:

2 milliseconds $/ 1000$ Words

12. CMOS-RAM protection:

13. Temperature limits:

Battery backup -

$0^{\circ} \mathrm{C}$ to $60^{\circ} \mathrm{C}$

14. Humidity:

$5 \%$ to $95 \%$ Relative Humidity (non-condensing)

F. Manufacturers

Possible manufacturers of this equipment include: Allen-Bradley, G.E. Fanuc, Modicon, Reliance Electric, Asea Brown Boveri Inc.

\subsubsection{Emplacement Gantry Programmable Logic Controller (PLC) Processor Data Sheet}
A. Equipment Name:
Emplacement Gantry Programmable Logic Controller
B. Service:
Monitor and control the operation of the emplacement gantry located underground in the emplacement drifts. 
C. Operating Conditions:

1. Working Location:

2. Elevation:

3. Temperature Range:

4. Humidity:

D. Power Requirements:

1. Input Voltage:

2. Frequency:

3. Wattage:

E. Equipment Description:

1. Mounting Requirements: Rack mounted

2. Number of Communication Ports:

3. Communication Protocols Supported:

4. VO Card Interface:

5. V/O card orientation

6. Type of cards supported:

7. I/O Capacity

8. Memory:

9. Program Scan Time:

10. CMOS-RAM protection:

11. Temperature limits:

12. Humidity:

F. Manufacturers

Possible manufacturers of this equipment include: Allen-Bradley, G.E. Fanuc, Modicon, Reliance Electric, Asea Brown Boveri Inc.
Below the surface in the emplacement drifts

Approximately 1000 to 1200 meters above sea level $10^{\circ} \mathrm{C}$ to $50^{\circ} \mathrm{C}$

TBD
120 Volts AC

$60 \mathrm{~Hz}$

As Required

\section{Minimum}

Ethernet TCP/IP, Data Highway, Remote Input/ Output (I/O), RS-232C, (ports to be user selectable) Yes

Local (ie. in the same rack as the processor)

Discrete, Analog, Intelligent 2048 I/O points

48,000 Words

2 milliseconds $/ 1000$ Words

Battery backup

$0^{\circ} \mathrm{C}$ to $60^{\circ} \mathrm{C}$

$5 \%$ to $95 \%$ Relative Humidity (non-condensing) 


\subsubsection{Programmable Logic Controller (PLC) Input/Output (VO) Chassis Data Sheet}

Modular V/O chassis are designed so that the L/O modules can be removed without turning off the AC power or removing the field wiring. H/O chassis can be mounted in a control panel or in an enclosure. The chassis generally come with either $4,8,12$, or 16 slots available for module mounting. The backplane of the V/O chassis has sockets for each module. These sockets provide the power and data communication connection to the processor. The backplane of the I/O chassis has a printed circuit card that contains the parallel communications bus to the processor and the DC voltages to operate the logic circuits within the I/O modules.
A. Equipment Name:
PLC I/O Chassis

B. Service:

House the PLC Processor and associated I/O cards required to monitor and control a particular operation.

C. Operating Conditions:

1. Working Location:

2. Elevation:

3. Temperature Range:

4. Humidity:

D. Power Requirements:

1. Input Voltage:

2. Frequency:

3. Wattage:
Below the surface in the main drifts (North, South, East, and West), on the emplacement gantry, on the transport locomotive, on the waste package transporter

Approximately 1000 to 1200 meters above sea level $10^{\circ} \mathrm{C}$ to $50^{\circ} \mathrm{C}$

TBD

120 Volts $A C$

$60 \mathrm{~Hz}$

As Required 
Title: WP Emplacement Control and

E. Equipment Description:

1. Mounting Requirements: Panel mountable

2. VO Module Slots:

4 Minimum

16 Maximum

3. PLC Processor:

Mountable in left-most slot

4. Cards supported:

Analog, Discrete, Intelligent

5. Maximum backplane current:

4 - slot:

16 Amps

8 - slot:

16 Amps

12 - slot:

24 Amps

16 - slot:

24 Amps

6. Temperature limits:

7. Humidity:

$0^{\circ} \mathrm{C}$ to $60^{\circ} \mathrm{C}$

$5 \%$ to $95 \%$ Relative Humidity (non-condensing)

F. Manufacturers

Possible manufacturers of this equipment include: Allen-Bradley, G.E. Fanuc, Modicon, Reliance Electric, Asea Brown Boveri Inc.

\subsubsection{Programmable Logic Controller (PLC) Discrete Input Card Data Sheet}

Discrete is the most common class of input/output in a programmable logic control system. This type of interface module connects field devices that have one of two states, such as open-close, on-off, to the processor. Each discrete input is designed to be activated by a field supplied voltage signal such as $120 \mathrm{VAC}, 24 \mathrm{VDC}$, etc. If an input switch is closed, the input circuitry on the card senses the supplied voltage and converts it to a logic-level signal acceptable to the processor to indicate the status of that device. The logic level signal is passed through to the PLC processor's data bus and stored in a memory location to be used within the PLC program.
A. Equipment Name:
PLC Discrete Input Card
B. Service:
Process discrete signals and convert them to a binary value for use by the PLC processor.


C. Operating Conditions:

1. Working Location:

2. Elevation:

3. Temperature Range:

4. Humidity:

D. Power Requirements:

1. Voltage:

2. Current draw:

3. Location of power:

E. Equipment Description:

1. Mounting Requirements:

2. Module mounting location:

3. Number of input channels:

4. Nominal input voltage:

5. Nominal input current:

6. On-state voltage range:

7. Maximum off-state voltage:

8. Temperature limits:

9. Humidity:
Below the surface in the main drifts (North, South, East, and West), on the emplacement gantry, on the transport locomotive, on the waste package transporter

Approximately 1000 to 1200 meters above sea level $10^{\circ} \mathrm{C}$ to $50^{\circ} \mathrm{C}$

TBD

\section{F. Manufacturers}

Possible manufacturers of this equipment include: Allen-Bradley, G.E. Fanuc, Modicon, Reliance Electric, Asea Brown Boveri Inc.

\subsubsection{Programmable Logic Controller (PLC) Analog Input Card Data Sheet}

The PLC analog input cards contain the circuitry necessary to accept analog voltage or current signals from field devices. The voltage or current inputs are converted from an analog to a digital value by an analog-to-digital converter (ADC) resident on the card. The converted value, in proportion to the analog signal, is passed through to the PLC processor's data bus and stored in a memory location to be used within the PLC program.
A. Equipment Name:
PLC Analog Input Card

O:URUDLRACZKALEDESDOC.WPD 
Title: WP Emplacement Control and

B. Service:

Process analog signals and convert them to a proportional binary value for use by the PLC processor.

C. Operating Conditions:

1. Working Location:

Below the surface in the main drifts (North, South, East, and West), on the emplacement gantry, on the transport locomotive, on the waste package transporter

2. Elevation:

3. Temperature Range:

4. Humidity: Approximately 1000 to 1200 meters above sea level $10^{\circ} \mathrm{C}$ to $50^{\circ} \mathrm{C}$ TBD

D. Power Requirements:

1. Voltage:

2. Current draw:

3. Location of power:

E. Equipment Description:

1. Mounting Requirements: I/O chassis mountable

2. Module mounting location: Single slot in VO chassis

3. Number of input channels:

4. Resolution:

5. Voltage Input Ranges:

6. Current Input Ranges:

7. Accuracy:

8. Repeatability:

9. Temperature limits:

10. Humidity:
5 Volts DC

As Required

Obtained from I/O chassis backplane

F. Manufacturers

Possible manufacturers of this equipment include: Allen-Bradley, G.E. Fanuc, Modicon, Reliance Electric, Asea Brown Boveri Inc.

12-bit binary

+1 to +5 VDC; 0 to +5 VDC; -5 to +5 VDC; -10 to +10 VDC

+4 to $+20 \mathrm{mADC} ; 0$ to $+20 \mathrm{mADC} ;-20$ to +20 $\mathrm{mADC}$

$0.1 \%$ of range

+1 Least Significant Bit

$0^{\circ} \mathrm{C}$ to $60^{\circ} \mathrm{C}$

$5 \%$ to $95 \%$ Relative Humidity (non-condensing)

O.RUDRACZRALQDESDOC.WPD 
Title: WP Emplacement Control and

\subsection{LEAKY FEEDER RADIO FREQUENCY COMMUNICATION EQUIPMENT}

This section provides a preliminary data sheet for a leaky feeder radio remote control system which is currently available to automate the operation of mobile emplacement vehicles such as locomotives, gantry, transport vehicles, and other repository machinery. The technology provides multiple channels of wide bandwidth, full color, frequency modulation (FM) video, voice, and data transmission and is currently used in underground mines. The system allows unmanned equipment to be remotely controlled and monitored throughout the operation, thus improving personnel safety and productivity. Complete communication networks of leaky coaxial cable have been installed throughout a mine, wherever communication is desired, to control and monitor large scale mining operations. The technology has been fully implemented in mines in Canada, Finland, Sweden, South Africa, and Australia. These systems are also used in U.S. government nuclear facilities for wireless remote control of cranes and radioactive material transfer machines.

As its name implies, a leaky coaxial cable or feeder is a transmission line that has a loosely attached shield, or slots cut in the shield of heliax type cable, which allow a carefully regulated amount of RF energy to leak out gradually and radiate power at each slot. The cable functions as a long, continuous antenna. This property allows for the radio signals to be carried over considerable distances underground by installing the cable in areas or spaces requiring radio coverage. The radio signal is radiated out of the leaky coaxial cable and coupled to the mobile radios that in turn receive the radio signal. Signal transmissions from a mobile radio are also picked up by the leaky coaxial cable and fed back to a remote control base station. Because the power is radiated gradually along the length of the cable, the distance can extend several hundred meters down a tunnel before bi-directional amplifiers may be required to boost the signal strength.

\subsubsection{Leaky Feeder Radio Communication Data Sheet}
A. Equipment Name:
Leaky Feeder radio communication system
B. Service:
Transmit and receive data and video signals to/from the mobile emplacement equipment.
C. Operating Conditions:
1. Working Location:
2. Elevation:
3. Temperature Range:
4. Humidity:
Below the surface in the main drifts (North, South, East, and West), and in all emplacement drifts. Approximately 1000 to 1200 meters above sea level $10^{\circ} \mathrm{C}$ to $+50^{\circ} \mathrm{C}$ (During emplacement operations) $10^{\circ} \mathrm{C}$ to $+200^{\circ} \mathrm{C}$ (During caretaker operations) TBD 
D. Power Requirements:

1. Voltage:

2. Current draw:

3. System operating voltage:
120 Volts AC

As Required

8 - 15 VDC

E. Equipment Description:

1. Mounting Requirements:

Cable:

Base station equipment:

On hangers or cable clips

Panel mount

2. No. of channels:

16 maximum

3. Frequency band:

$20 \mathrm{MHZ}$ to $115 \mathrm{MHZ}$

4. In/Out Impedance:

75 Ohms

5. Amplifier gain:

6. Gain Adjustment Range:

7. Signal repeaters:

8. Agency approval:

manual gain adjustment $=4$ to $17 \mathrm{~dB}$

$10 \mathrm{~dB}$

as required

UL, CSA

F. Manufacturers

Possible manufacturers of this equipment include: Mine Radio Systems Inc., El-Equip Inc., Automated Mining Systems Inc.

\subsection{SLOTTED MICROWAVE GUIDE COMMUNICATION EQUIPMENT}

Slotted microwave guide communication systems operate in a manner very similar to the leaky coaxial cable radio systems. Instead of the radiating coaxial cable, a slotted waveguide is used to confine the microwave energy and direct the signal from a fixed antenna inside the metal channel to a mobile antenna. The mobile antenna travels inside a slot, along the waveguide, where it receives and transmits data from its on-board control system, such as a PLC, to the stationary monitoring equipment.

The system consists of a stationary transceiver that could be located at the entrance of an active emplacement drift, a $600 \mathrm{~m}$ long slotted microwave guide consisting of an inverted metal channel; a mobile antenna that travels along the wave guide and fits inside the slotted opening without contact, and a mobile transceiver that is mounted on the remotely operated emplacement vehicle. The mobile antenna would extend from the emplacement vehicle to engage the wave guide. The system is capable of full duplex operation using two carrier frequencies, $2.4 \mathrm{GHz}$ for command and control signals to the vehicle and $2.5 \mathrm{GHz}$ for data and video signals back to the operator. 
The traveling antenna does not contact the wave guide, but the actual air gap is only a few $\mathrm{mm}$. A traveling collector bracket can be furnished to ensure this separation between the antenna and wave guide is maintained as the antenna travels along the wave guide. Because the antenna is closely coupled to the wave guide, data integrity is assured due to the wave guides immunity to external electromagnetic and radio frequency interference sources. The connection between the traveling antenna and the mobile equipment is via flexible cable so installation variations between the wave guide and track or rail can be accommodated. A $300 \mathrm{MHZ}$ band is available to carry data, audio, and multi-channel video signals. The system is capable of transmitting signals over $1,000 \mathrm{~m}$ without amplification or loss of signal. The system is easy to install and has no moving parts to maintain other than the mobile antenna travel guide that is located on the emplacement vehicle.

This technology is currently used in high speed rail, monorails, bridge cranes, people movers, elevators and all types of material handling systems. High speed rail trains traveling at more than $\mathbf{4 0 0}$ kilometers/hour have successfully used this technology for over ten years. It is very well suited for mobile applications with a fixed path or guide way, such as the rail system in the emplacement drifts of the underground repository.

\subsubsection{Slotted Microwave Guide System Data Sheet}

A. Equipment Name:

B. Service:

C. Operating Conditions:

1. Working Location:

- 2. Elevation:

3. Temperature Range:

4. Humidity:

D. Power Requirements:

1. Voltage:

2. Current draw:
Slotted microwave guide communication system

Transmit and receive data and video signals to/from the mobile emplacement equipment.

Below the surface in all emplacement drifts. Approximately 1000 to 1200 meters above sea level $-10^{\circ} \mathrm{C}$ to $+50^{\circ} \mathrm{C}$ (During emplacement operations) $-10^{\circ} \mathrm{C}$ to $+200^{\circ} \mathrm{C}$ (During caretaker operations) TBD

120 Volts AC

As Required 
Title: WP Emplacement Control and Communication Equipment Descriptions

E. Equipment Description:

1. Mounting Requirements:

Slotted Waveguide: On hangers or brackets

Base station equipment: Panel mount

2. No. of channels: 6 maximum

3. Carrier frequency: $\quad 2.4 \mathrm{GHz}$ to $2.5 \mathrm{GHz}$

4. Signal bandwidth: $\quad 300 \mathrm{MHZ}$

5. Data rates:

Single channel: $\quad 10 \mathrm{Mbps}$

Six channels: $\quad 187 \mathrm{kbps}$

6. Waveguide material: Aluminum

7. Data interfaces: RS-232, RS-422, RS-485, Ethernet

8. Signal repeaters: as required

9. Agency approval: UL, CSA

F. Manufacturers

Possible manufacturers of this equipment include: Vahle Electrification Systems, Electromagnetics Corp.

\subsection{VISION SYSTEMS}

Remotely controlled camera systems for use in hostile and elevated radiation environments are readily available from commercial sources. For additional information on vision system technologies, refer to input 2.3, Section 7.5.4, "Instruments for Remote Monitoring and Data Collection", and the associated attachments, Attachment II "Electronic Components \& Technologies for Elevated Radiation environments", and Attachment V, "Remote Manipulation, Inspection and Sensing Technologies for Hazardous Environments". Note: although these references relate to equipment design concepts anticipated during Performance Confirmation, the technologies and strategies discussed therein are also applicable in developing equipment for use during initial Emplacement Operations.

\subsubsection{Vision System Data Sheet}
A. Equipment Name:
Color Camera System

B. Service:

Remote control camera system with auto focus and auto zoom and rated for use in nuclear environments. 
C. Operating Conditions:

1. Working Location:

2. Temperature Range:

3. Humidity:

D. Power Requirements:

1. Input Voltage:

2. Frequency:

3. Power Consumption:

4. Camera Power:

E. Equipment Description:

1. Mounting Requirements:

Camera:

Camera Control Unit:

2. Operating Weight:

Camera:

Camera Control Unit:

3. Camera Element:

4. Scan Area:

5. Scanning Frequency:

6. Sync

7. Temperature Range:

8. Humidity:

9. Radiation Tolerance:
Mounted on mobile emplacement gantry. Operated in a subsurface tunnel and drift environment.

$10^{\circ} \mathrm{C}$ to $50^{\circ} \mathrm{C}$

TBD

Camera Control Unit, 110/120 Volts AC

$50 / 60 \mathrm{~Hz}$

Approximately $10 \mathrm{VA}$

40 watts

Stainless Steel Tube, 1.6" in diameter

rack mount, 19"x 15"x 15.2"

$2.7 \mathrm{lbs}$

$18.3 \mathrm{lbs}$

$1 / 2$ inch Interline-transfer CCD, 570 Horizontal by 485

Vertical picture elements.

$0.252^{\prime \prime} \times 0.192^{\prime \prime}$

2:1 Interlaced, $15.7 \mathrm{kHz}$ Horizontal, $59.94 \mathrm{~Hz}$ Vertical Internal/External Sync

$-25^{\circ} \mathrm{C}$ to $55^{\circ} \mathrm{C}$

95\% Relative Humidity, Noncondensing, Optional waterproof construction available.

$2 \times 10^{8}$ rads total dose, with greater than $3 \times 10^{6}$ rads per hour maximum dose rate.

F. Manufacturers

Rees Instruments Inc., 1900 Lake Park Drive, Suite 310, Smyrna, Georgia, 30080, USA, (404) 433-9991 


\subsection{RADIO CONTROL EQUIPMENT}

For additional information on radio communication and control technologies refer to inputs 2.1, 2.2, and 2.3, Attachment III, "Power \& Communication Technologies for Remotely Operated Systems".

\subsubsection{Radio Control Equipment Data Sheet}
A. Equipment Name:
Wireless Radio Modem

B. Service:

Provide high performance, high data rate, wireless LAN connections for mobile equipment.

C. Operating Conditions:

1. Working Location:

2. Temperature Range:

3. Humidity:

D. Power Requirements:
1. Input Voltage:
2. Input Amperage:
3. Standards

E. Equipment Description:

1. Mounting Requirements:

2. Operating Weight:

3. Radio/Modem Freq.

4. Radio Type:

5. Transmission Power:

6. Data Rate

7. Cell Size:

Open Air:

Indoor:

8. Overlapping Cells

9. Wireless LAN Interface:

10. Temperature Range:

11. Humidity:
Mounted on mobile equipment. Operated in a subsurface tunnel and drift environment. $10^{\circ} \mathrm{C}$ to $50^{\circ} \mathrm{C}$

TBD
5 VDC $1200 \mathrm{~mA}$

UL, UUC, TUV/GS, FCC Part 15.247, ETS 300-328
Dimensions 5.1"x 3.4"x 1.2"

$1 \mathrm{lb}$

$2.4-2.4835 \mathrm{GHz}$

Spread spectrum frequency hopping 10 or $100 \mathrm{~mW}$

1,2 or $3 \mathrm{Mbps}$

3000 feet

200-600 feet

17

Standard IEEE 802.11 (D2 Draft), Media Access Protocol: CSMA/CA, Number of stations per cell, 256 maximum.

$0{ }^{\circ} \mathrm{C}$ to $40{ }^{\circ} \mathrm{C}$

5\%-95\% Non-condensing Relative Humidity 
Title: WP Emplacement Control and

F. Manufacturers

Breeze Wireless Communications Inc., 2195 Faraday Ave, Suite A, Carlsbad, CA 92008, (619) 431-9880

\subsection{ENCLOSURE COOLING SYSTEMS}

Emplacement Gantry Instrumentation Enclosure Coolers. For additional information on additional cooling technologies and strategies refer to input 2.3, Section 7.5.2, "Technologies for Elevated Temperatures", and the associated attachment, Attachment I "Electronic Technologies and Design Strategies for Elevated Temperature Environments". Note: although these references relate to equipment design concepts for operation at the higher temperatures anticipated in the Emplacement Drifts during Performance Confirmation, the technologies and strategies discussed therein are also applicable in developing equipment for use during initial Emplacement Operations.

\subsubsection{Enclosure Cooling System Data Sheet}
A. Equipment Name:
Enclosure Cooling
B. Service:
Cooling electrical enclosures
C. Operating Conditions:

1. Working Location:

2. Elevation:

3. Temperature Range:

4. Humidity:

D. Power Requirements:

1. Input Voltage:

2. Frequency:

3. Max Load Amps:

E. Equipment Description:

1. Mounting Requirements:

2. Operating Weight:

3. BTU/H Capacity:

4. Refrigerant:
Mounted on mobile emplacement gantry. Operated in a subsurface tunnel environment Approximately 1000 to 1200 meters above sea level $10^{\circ} \mathrm{C}$ to $50^{\circ} \mathrm{C}$

TBD
120 Volts AC, single phase $60 \mathrm{~Hz}$ 15 Amps
NEMA 12 Enclosure Rating, Panel Mounted, 19" x 37.75"

$109 \mathrm{lbs}$ $6000(1512 \mathrm{kcal} / \mathrm{hr})$

HFC-134a coolant, 25 oz charge 
Title: WP Emplacement Control and

5. Control:

6. Temperature Range:

7. Humidity:

F. Manufacturers
Closed loop System, Thermostatically controlled $21^{\circ} \mathrm{C}$ to $52^{\circ} \mathrm{C}$ $10 \%$ to $95 \%$ Relative Humidity

Possible manufacturers of this equipment include: ITW Vortec, 10125 Carver Road, Cincinnati, Ohio, 45242-9978, (513)-891-7485

\subsection{CONCLUSION}

The equipment described in this document has been presented and discussed in related analyses during fiscal year 1996 and 1997 and was found to be suitable for control of the waste emplacement process. All of the recommended control and communication equipment can be manufactured from off-theshelf components. Further investigation and possible prototyping will be necessary to ensure that the equipment described herein will function correctly under expected repository conditions. 